\title{
Very High Frequency Resonant DC/DC Converters for LED Lighting
}

\section{Madsen, Mickey Pierre; Knott, Arnold; Andersen, Michael A. E.}

Published in:

2013 IEEE Applied Power Electronics Conference and Exposition

Publication date:

2013

Document Version

Publisher's PDF, also known as Version of record

Link back to DTU Orbit

Citation (APA):

Madsen, M. P., Knott, A., \& Andersen, M. A. E. (2013). Very High Frequency Resonant DC/DC Converters for LED Lighting. In 2013 IEEE Applied Power Electronics Conference and Exposition (pp. 835-839). IEEE.

\section{General rights}

Copyright and moral rights for the publications made accessible in the public portal are retained by the authors and/or other copyright owners and it is a condition of accessing publications that users recognise and abide by the legal requirements associated with these rights.

- Users may download and print one copy of any publication from the public portal for the purpose of private study or research.

- You may not further distribute the material or use it for any profit-making activity or commercial gain

- You may freely distribute the URL identifying the publication in the public portal

If you believe that this document breaches copyright please contact us providing details, and we will remove access to the work immediately and investigate your claim. 


\title{
Very High Frequency Resonant DC/DC Converters for LED Lighting
}

\author{
Mickey P. Madsen*, Arnold Knott*, Michael A. E. Andersen* \\ *Technical University of Denmark \\ Ørsteds Plads, bygning 349 \\ 2800 Kongens Lyngby \\ Denmark \\ Email: \{mpma, akn,ma\}@elektro.dtu.dk
}

\begin{abstract}
This paper presents a very high frequency DC/DC converter for LED lighting. Several resonant topologies are compared and their usability discussed. At the end the resonant SEPIC converter is chosen based on the achievable power density and total bill of material. Simulations of a $51 \mathrm{MHz}$ converter with $40 \mathrm{~V}$ input and $15 \mathrm{~V}$ output are made. The simulation shows possibility of achieving efficiency up to $87 \%$ even with a HEXFET Power MOSFET. Three prototypes of the simulated converter are implemented showing good correlation with simulations. The prototypes have efficiencies up to $84 \%$ and power densities up to $8.9 \mathrm{~W} / \mathrm{cm}^{3}\left(146 \mathrm{~W} / \mathrm{in}^{3}\right)$.
\end{abstract}

\section{INTRODUCTION}

During the last decade the focus on green and environment friendly energy usage has been constantly increasing. This has lead to a large increase in the use of Light-Emitting Diodes (LEDs) for lightning. These bulbs are still quite expensive due to both expensive LEDs and the power converter needed to supply these. Hence there is a strong demand for small, cheap and efficient power converters.

The power density of Switch-Mode Power Supplies (SMPS) is limited by their passive energy storing elements. As both the physical size and price of these scale with the switching frequency $\left(f_{S}\right)$, increasing $f_{S}$ into the Very High Frequency band (VHF, 30-300 MHz) will make it possible to achieve higher power density and lower cost. Increasing the switching frequency has several other advantages, which has been discussed in [4], [6], [15] and [16].

The high increase in $f_{S}$ causes several new problems to arise. Some of these have been solved [4], [11] and [18], but many still need to be investigated. One of the main problems is the switching loss, which increases linearly with $f_{S}$. As $f_{S}$ increases into the VHF band the switching losses becomes so severe that it will be impossible to cool the switching device and keep the efficiency high. Several researchers [2]- [5] and [7] have tried to use different types of resonant converters with Zero Voltage Switching (ZVS) and/or Zero Current Switching (ZCS) in order to reduce or ideally eliminate these losses.

Due to the resonating behaviour of these converters it is however very difficult to control these converters for varying loads efficiently. For now the most efficient way is to use burst mode control to simply Pulse Width Modulate (PWM) the converter in order to achieve the desired output [4], [9] and [21].
When working continuously in open loop these converters will have an almost constant current output for a given input voltage. This makes them very well suited for LED applications where it is the current that needs to be controlled. As the output current is constant for a given input voltage the current through the LED will be constant even as the forward voltage changes due to changes in temperature. The life time of LED bulbs are limited by the electrolytic capacitors needed, increasing the switching frequency will eliminated this need and hence increase the life time of the bulb.

This paper will give an example of the design of a VHF resonant DC/DC converter for LED lighting. First an appropriate topology is selected in section II, then the a simulation is made and component selected in section III. Section IV covers the implementation and measurements and finally section $\mathrm{V}$ concludes the paper.

\section{SElection of TOPOLOGY}

When designing resonant DC/DC converters it is very common to split the converter in to two parts; 1) a resonant inverter converting the DC input voltage to a sinusoidal output current 2) a resonant rectifier rectifying the $\mathrm{AC}$ current to a DC output [1], [8], and [14].

The most commonly used rectifier is the class $\mathrm{E}$ rectifier [8], [17] and [19]. Other alternatives exist [1], [7] and [10], but due to the very simple schematic with a single diode the class $\mathrm{E}$ rectifier is chosen for this converter.

For the inverter part several topologies has been used [2], [3] and [5], each with their own pros and cons.

The class DE inverter (used in [5], [10] and [11] and shown together with the selected rectifier in Figure 1) is the topology with the lowest stress on the switches due to the direct connection to the input, but it requires a high side driver. This is complex to design for these frequencies and it will increase both the complexity, size and price of the converter.

The class E inverter (used in [6] and [8]) shown in Figure 2 has only a low side switch and is therefore much simpler to drive, however it imposes a huge voltage stress on the switch. As the drain of the switch is connected to the input through an inductor, the average drain-source voltage $\left(V_{D S}\right)$ of the switch has to be equal to the input voltage. Even if $V_{D S}$ is assumed constant when the switch is closed, the peak voltage will be 


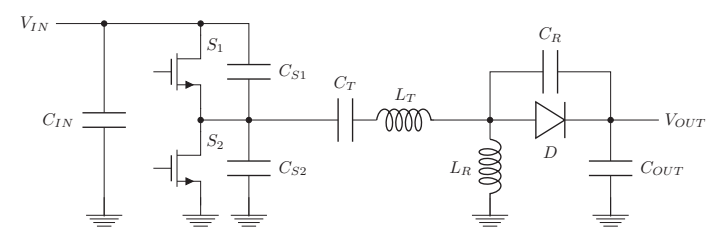

Fig. 1. Schematic of the class DE inverter and class E rectifier.

two times $V_{I N}$ for a duty cycle of $50 \%$. In reality the voltage across the switch is more like a half wave rectified sine wave in order to achieve ZVS, which result in a peak voltage of 3.56 times $V_{I N}[12]$.

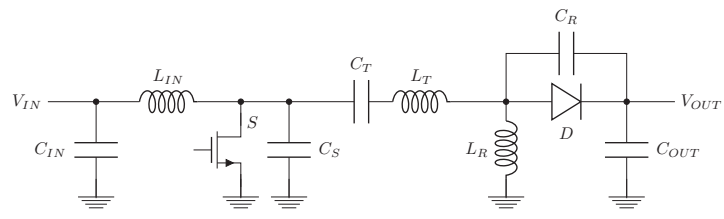

Fig. 2. Schematic of the class E inverter and rectifier.

In order to reduce this huge peak voltage the class $\mathrm{EF}_{2}$ (or $\varphi_{2}$ ), which is a hybrid between the class $\mathrm{E}$ and class $\mathrm{F}_{2}$, has been developed ( [13] and [14]). It introduces an extra resonant circuit $\left(C_{M R}\right.$ and $L_{M R}$ in Figure 3$)$ across the drain and source of the switch with a zero at the second harmonic of $f_{S}$. If tuned correctly this adds the third harmonic of $f_{S}$ on top of the sine wave seen with the class E. This results in a trapezoidal waveform across the switch. This reduces the peak voltage a bit, but increases complexity and results in additional losses due to large $\mathrm{AC}$ current at three times $f_{S}$.

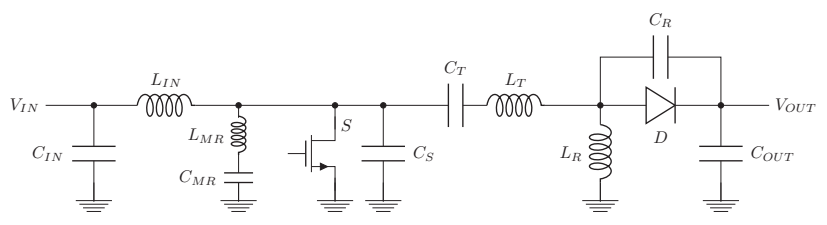

Fig. 3. Schematic of the class $\mathrm{EF}_{2}$ inverter and class $\mathrm{E}$ rectifier.

The SEPIC converter [20] shown in Figure 4 is similar to the circuit in Figure 2 with $L_{T}$ removed. However the waveforms are different, as this converter cannot be split into an inverter and a rectifier. The changed waveforms results in a much smaller input inductor than needed for the class $\mathrm{E}$ inverter, thus the achievable power density is higher due to fewer and smaller inductors.

Based on the analysis of the four converter topologies the SEPIC converter was chosen as it gives the highest power density and lowest cost.

\section{Simulation AND COMPONENT SELECTION}

A model of a resonant SEPIC converter has been set up in spice based on the tuning procedure explained in [20]. The converter is designed to have the specifications given in table

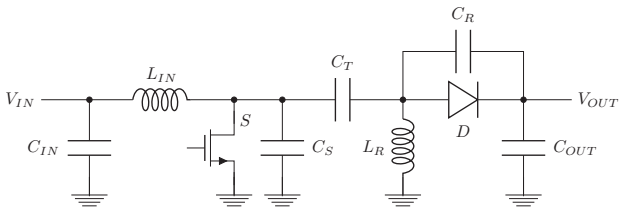

Fig. 4. Schematic of the SEPIC converter.

I. The converter will be used to supply a string of LEDs with a combined forward voltage drop of $12-15 \mathrm{~V}$, depending on temperature and power level.

TABLE I

DESIGN SPECIFICATIONS

\begin{tabular}{c|c|c}
\hline Specification & Symbol & Value \\
\hline \hline Input voltage & $V_{I N}$ & $40 \mathrm{~V}$ \\
\hline Output power & $P_{O U T}$ & $5 \mathrm{~W}$ \\
\hline Output Voltage & $V_{O U T}$ & $15 \mathrm{~V}$ \\
\hline Switching frequency & $f_{S}$ & $51 \mathrm{MHz}$ \\
\hline
\end{tabular}

From the simulations it is seen that the MOSFET should have a break down voltage of at least 100V (see Figure 6), however if the duty cycle is adjusted closer to $50 \%$ the peak voltage will get close to $143 \mathrm{~V}$ (3.56 times the input voltage as for the class E). For this reason it was decided to build the prototype around an IRF5802 MOSFET from International Rectifier. The MOSFET has a break down voltage of $150 \mathrm{~V}$ and small parasitic capacitances compared to its competitors.

The peak voltage is slightly above $40 \mathrm{~V}$ (see Figure 6 where $\mathrm{V}_{A C}$ is anode-cathode voltage) and a MBR0540 40 $\mathrm{V}$ Schottky diode has therefore been selected. $\mathrm{C}_{R}$ needs to be $105 \mathrm{pF}$ which is more than the parasitic capacitance of a single diode $(35 \mathrm{pF})$, thus it is necessary either to add a $70 \mathrm{pF}$ capacitor or use three diodes in parallel. The last solution have the benefit of sharing the current between the three devices. As the forward voltage drop of the diodes increases with the current running through them, this will lead to reduced losses and this solution was therefore selected.

The inductors are all square air core inductors (1515SQ$68 \mathrm{~N}, 1515 \mathrm{SQ}-82 \mathrm{~N}$ and 2222SQ-161) as they have a fairly high $\mathrm{Q}$ factor and are available off the shelf which ease implementation. The $\mathrm{C}_{T}$ capacitor is implemented with 4 parallel capacitors as it was found that this increased the efficiency of the converter with 1-2\% compared to using a single capacitor of the same value. For the input and output capacitors standard $1 \mu \mathrm{F}$ X7R capacitors was selected.

\section{IMPLEMENTATION AND MEASUREMENTS}

A prototype of the simulated converter has been implemented and is shown in Figure 7. The prototype had an efficiency of $84 \%$, this is slightly lower than the simulated efficiency but still on level with other state of the art VHF converters. The output power was $5.7 \mathrm{~W}$ at $40 \mathrm{~V}$ input, which is significantly higher than the expected. The increase in output 

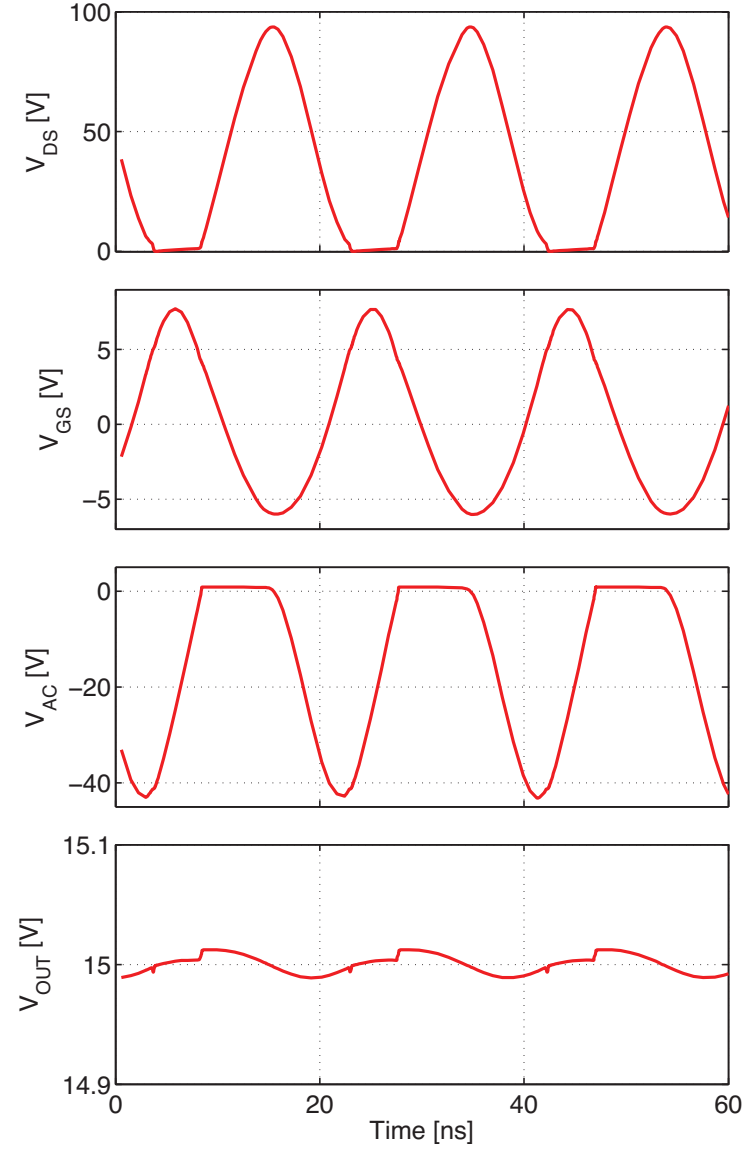

Fig. 5. Simulation results

TABLE II

BILL OF MATERIALS

\begin{tabular}{c|c|c|c}
\hline Component & Simulated & Prototype & Type \\
\hline \hline$C_{I N}$ & $1 \mu F$ & $1 \mu F$ & Capacitor (X7R) \\
\hline$L_{I N}$ & $160 n H$ & $160 n H$ & Inductor \\
\hline$S$ & & IRF5802 & n-channel MOSFET \\
\hline$C_{S}$ & $22 p F$ & Parasitic & Capacitor \\
\hline$C_{T}$ & $40 p F$ & $4 \cdot 10 p F$ & Capacitor (NPO) \\
\hline$L_{R}$ & $82 n H$ & $82 n H$ & Inductor \\
\hline$D$ & & $3 \cdot$ MBR0540 & Schottky diode \\
\hline$C_{R}$ & $105 p F$ & Parasitic & Capacitor \\
\hline$C_{O U T}$ & $1 \mu F$ & $1 \mu F$ & Capacitor (X7R) \\
\hline
\end{tabular}

power was achieved by reducing the switching frequency to $46 \mathrm{MHz}$ and increasing the duty cycle.

The gate and output voltages were measured with the standard probes for a Rohde \& Schwartz RTO1024 digital oscilloscope. The capacitance of the probes are $10 \mathrm{pF}$, adding this between the drain and source of the MOSFET would change the resonance of the converter making it hard switch and thereby destroy the switch. To avoid this a voltage divider was made by adding a $1 \mathrm{pF}$ capacitor in series with the probe, this reduces the effectively added capacitance to $0.9 \mathrm{pF}$. This
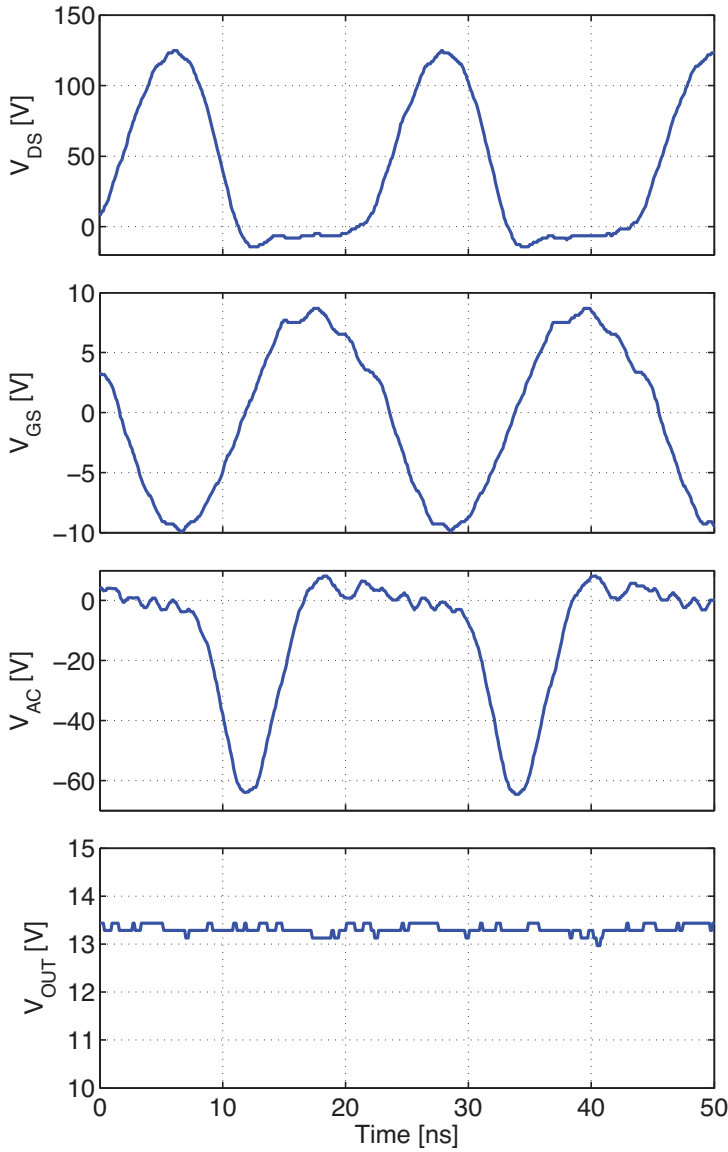

Fig. 6. Measured waveforms

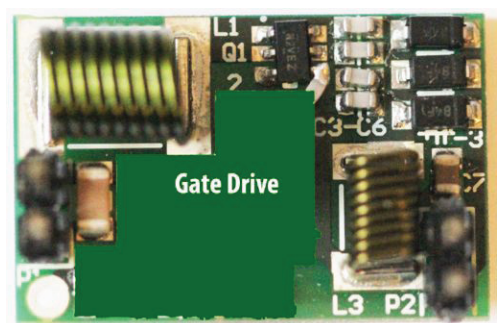

Fig. 7. Picture of the implemented prototype on a $15 \times 22 \mathrm{~mm}$ PCB

still affect the behaviour of the converter, however as seen in Figure 6 the converter is still operating close to ZVS. In order to get the correct DC level a resistive voltage divider was added in parallel with the probe and the $1 \mathrm{pF}$ capacitor. The same principle was used to measure the voltage at the anode of the diode, at this node $10 \mathrm{pF}$ would not be as crucial but it is still necessary to keep the converter close to ZVS.

From the measured waves it seems like the gate drive is a few nano second to slow when turning on the MOSFET. Whether this is actually happening or if it is due to a small delay caused by the resistive/capacitive voltage division made to measure the drain voltage is not certain. If the gate drive is actually turning on the MOSFET to late, it is partly saved 


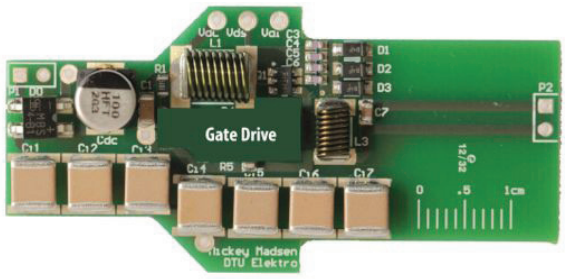

(a) Top of offline prototype

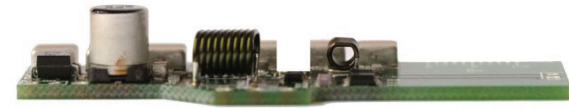

(c) Front of offline prototype

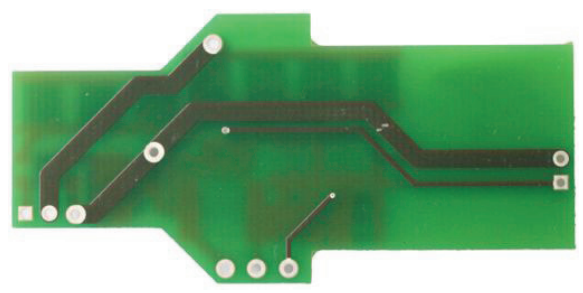

(e) Bottom of offline prototype

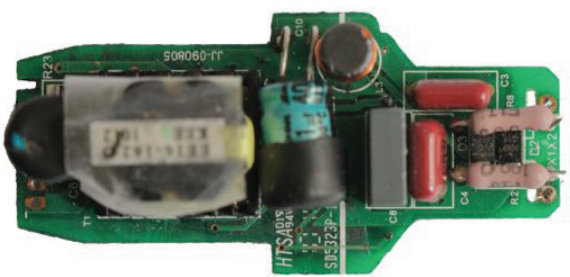

(b) Top of commercial supply

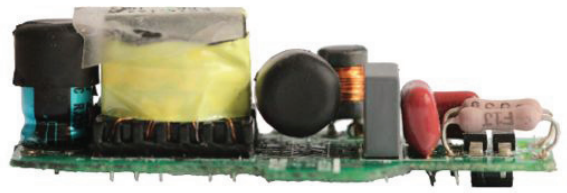

(d) Front of commercial supply

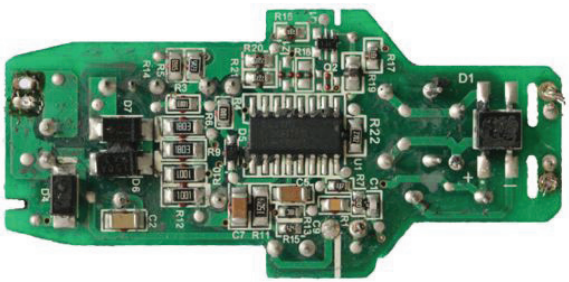

(f) Bottom of commercial supply

Fig. 8. Comparison of first VHF based prototype and commercial available $230 \mathrm{~V}$ power supply

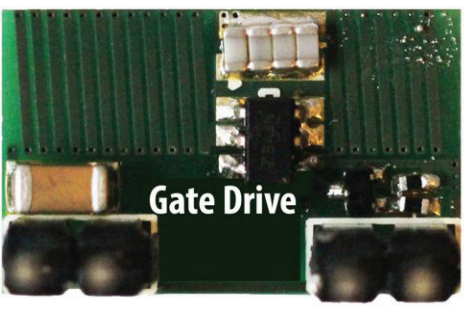

Fig. 9. Top side of prototype with PCB inductors (10x16mm PCB)

by the body diode of the MOSFET and the efficiency can therefore still be acceptable. However in this situation fine tuning of the gate drive could increase efficiency a few percent as the body diode is a quite lossy device.

The peak voltage across the diode is far above the rated limit. This is mainly caused by the reduced switching frequency which makes the impedance of the inductor decrease while the impedance of the parasitic capacitance increase, this increases the duty cycle of the diode and there by increases the peak voltage. The increased power is also contributing to an increased peak voltage, but this will only cause a slight increase.

The ripple seen at the output is clearly some digital noise cause by the oscilloscope and not something that can be used to determine the output ripple of the converter.

\section{A. Alternative implementations}

The main reason for the increasing the output power was to get the same amount of power as the commercial supply shown in Figure 8(b), 8(d) and 8(f). This supply is made for the european mains $(230 \mathrm{~V})$ and has an efficiency of 77 $\%$, i.e. $7 \%$ below the $40 \mathrm{~V}$ VHF converter with the same output in a much smaller footprint. In order to make a fair comparison a prototype was made with a mains rectifier and a capacitive voltage divider to reduce the input voltage of the VHF converter (the offline prototype is shown in Figure 8(a), $8(\mathrm{c})$ and $8(\mathrm{e}))$. The offline prototype has an efficiency of 78 $\%$ and a volume which is reduced by approximately $80 \%$ compared to the commercial supply. Hence it offers slightly increased efficiency in a dramatically reduced volume.

It should however be noted that the power factor of the offline prototype is very poor (below 0.5 ) whereas the commercial has a power factor of 0.82 . Furthermore the commercial supply is galvanic isolated which the offline prototype is not.

In order to push the power density even further, a prototype has been made were the inductors are implemented as PCB solenoids. The complete converter has a footprint of $16 \times 10 \times 4$ $\mathrm{mm}(\mathrm{LxWxH})$ and can handle an output power of up to $5 \mathrm{~W}$. This gives a power density of $7.8 \mathrm{~W} / \mathrm{cm}^{3}$ and if the connectors (2 times $2 \times 5 \mathrm{~mm}$ on the $\mathrm{PCB}$ ) are disregarded the power density is $8.9 \mathrm{~W} / \mathrm{cm}^{3}\left(146 \mathrm{~W} / \mathrm{inch}^{3}\right)$. All the components used for this prototype are the same as for the one shown in Figure 7 (except for the inductors), but both sides of the PCB has been used. The series resistances of the PCB inductors are a 
bit higher than their discrete counter parts and this causes the efficiency to drop to $80 \%$.

\section{CONClusion}

A very compact and cheap converter with state of the art efficiency for VHF converters has been implemented. It is shown that resonant VHF converters using standard MOSFETs can be implemented reducing price and making it possible to design for higher input voltages.

The paper has covered three different prototypes; 1) a basic design of a resonant SEPIC converter with a standard nchannel MOSFET and $84 \%$ efficiency, 2) a offline $\left(230 \mathrm{~V}_{A C}\right)$ prototype with a volume reduced by $80 \%$ compared to a commercial supply and 3) a prototype with PCB inductors and a power density of $8.9 \mathrm{~W} / \mathrm{cm}^{3}$.

\section{REFERENCES}

[1] Marian K. Kazimierczuk \& Dariusz Czarkowski, Resonant Power Converters, John Wiley \& Sons, New. York, 2011.

[2] Marian K. Kazimierczuk, RF Power Amplifiers, John Wiley \& Sons, New. York, 2008.

[3] Andrei Grebennikov \& Nathan O. Sokal, Switchmode RF Power Amplifiers, Newnes, Burlington, 2007

[4] Juan Rivas, Radio Frequency dc-dc Power Conversion, Doctoral Thesis, Massachusetts Institute of Technology, 2006.

[5] Ian Douglas de Vries, High Power and Frequency Class-DE Inverters, Doctoral Thesis, University of Cape Town, 1999.

[6] Toke M. Andersen, A VHF Class E DC-DC Converter with SelfOscillating Gate Driver, in IEEE 2011 Applied Power Electronics Conference, 2011, pp. 885-891.

[7] W. C. Bowman, J. F. Balicki et al., A resonant DC-to-DC converter operating at 22 megahertz, in IEEE 1988 Applied Power Electronics Conference, 1988, pp. 3-11.

[8] Marian K. Kazimierczuk and Jacek Jozwik, Resonant dc/dc Converter with Class-E Inverter and Class-E Rectifier, in IEEE Transactions on Industrial Electronics, vol. 36, no. 4, pp. 468-478, Nov 1989.

[9] James R. Warren, III, Kathryn Anne Rosowski and David J. Perreault, Transistor Selection and Design of a VHF DC-DC Power Converter, in IEEE Transactions on Power Electronics, vol. 23, no. 1, pp. 27-37, Jan. 2008.

[10] David C. Hamill, Class DE Inverters and Rectifiers for DC-DC Conversion, in IEEE 1996 Power Electronics Specialists Conference, 1996, pp. 854-860.

[11] David C. Hamill, Impedance plane analysis of class DE amplifier, in IEEE Electronics Letters, vol. 30, no. 23, pp. 1905-1906, 10 Nov 1994.

[12] Z. Kaczmarczyk, High-Efficiency Class E, EF2, and E/F3 Inverters, in IEEE Transactions on Industrial Electronics, vol. 53, pp. 15841593, Oct. 2006.

[13] Juan M. Rivas, Yehui Han et al., A High-Frequency Resonant Inverter Topology with Low Voltage Stress, in IEEE Transactions on Power Electronics, vol. 23, no. 4, pp. 1759- 1771, July 2008.

[14] Juan M. Rivas, Olivia Leitermann et al., A Very High Frequency $d c-d c$ Converter Based on a Class $\varphi_{2}$ Resonant Inverter, in IEEE 2008 Power Electronics Specialists Conference, 2008, pp.1657-1666.

[15] John S. Glaser and Juan M. Rivas, A 500 W Push-pull Dc-dc Power Converter with a $30 \mathrm{MHz}$ Switching Frequency, in IEEE 2010 Applied Power Electronics, 2010, pp. 654- 661.

[16] David J. Perreault, Jingying Hu, Juan M. Rivas et al., Opportunities and Challenges in Very High Frequency Power Conversion, in IEEE 2009 Applied Power Electronics Conference, 2009, pp.1-14.

[17] Juan M. Rivas, David Jackson, Olivia Leitermann et al., Design Considerations for Very High Frequency dc-dc Converters, in IEEE 2006 Power Electronics Specialists Conference, 2006, pp.1-11.

[18] Yehui Han, Olivia Leitermann, David A. Jackson et al., Resistance Compression Networks for Radio-Frequency Power Conversion, in IEEE Transactions on Power Electronics, vol. 22, no. 1, pp. 41-53, Jan. 2007.

[19] John S. Glaser, Jeffrey Nasadoski and Richard Heinrich, A 900W, 300V to $50 \mathrm{~V} \mathrm{Dc-dc}$ Power Converter with a $30 \mathrm{MHz}$ Switching Frequency, in IEEE 2009 Applied Power Electronics Conference, 2009, pp. 1121-1128.
[20] Jingying Hu, Anthony D. Sagneri, Juan M. Rivas et al., High Frequecny Resonant SEPIC Converter with Wide Input and Output Voltage Ranges, in IEEE 2008 Power Electronics Specialists Conference, 2008, pp.13971406.

[21] Robert C. N. Pilawa-Podgurski, Anthony D. Sagneri, Juan M. Rivas et al., Very High Frequency Resonant Boost Converters, in IEEE 2007 Power Electronics Specialists Conference, 2007, pp. 2718-2724. 